\title{
Animal model of rapid crystalloid infusion in rats $^{1}$
}

\author{
Flavio Stillitano Orgaes ${ }^{I}$, Fausto Viterbo de Oliveira Neto ${ }^{\text {II }}$, Flavio Henrique Mendes ${ }^{\text {III }}$, Renato Florio Yabiku ${ }^{\text {IV }}$
}

IFellow Master degree, Postgraduate Program in Surgery Bases, Department of Surgery and Orthopedics, Faculty of Medicine of Botucatu, UNESP, Brazil. Main author. Conception, design, scientific and intellectual content of the study; acquisition and interpretation of data; manuscript writing. IIPhD, Associate Professor, Department of Surgery and Orthopedics, Faculty of Medicine of Botucatu, UNESP, Brazil. Supervised all phases of the study, scientific and intellectual content of the study, manuscript writing, critical revision.

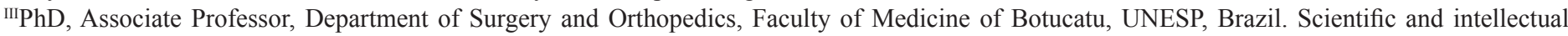
content of the study, manuscript writing, critical revision.

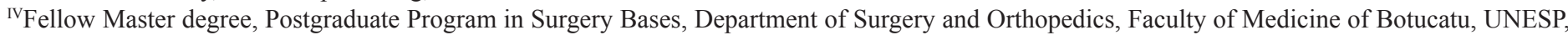
Brazil. Acquisition of data.

\section{ABSTRACT}

PURPOSE: To describe an animal model of rapid intravenous infusion with different volumes of crystalloid and discuss the clinical findings.

METHODS: Fifty six male Wistar rats were used, divided randomly in seven groups $(\mathrm{n}=8)$. The rats of groups 1 to 6 received lactated Ringer's solution intravenously, in the rate of $25 \mathrm{ml} / \mathrm{min}$, with different volumes proportional to blood volume (BV). The rats of group 0 were submitted to the same procedure, but did not receive the fluid (control group). The data included respiratory rate, heart rate, saturation of peripheral oxygen $\left(\mathrm{SpO}_{2}\right)$ in two times (before and after the infusion), and upshots (respiratory arrest and death). Dunnett's test and ANOVA were used.

RESULTS: The clinical signs significantly changed in the 2, 2.5 and 3 fold BV groups. The respiratory arrest was observed in the 1.5 , 2, 2.5 and 3 fold BV groups, but death was present only in 2.5 and 3 fold BV groups.

CONCLUSIONS: The infusion of crystalloid in the same volume of blood volume did not cause significant variation in respiratory and heart rate, saturation of peripheral oxygen and did not induce respiratory arrest. The infusion of a volume of 3 fold blood volume was lethal to all animals.

Key words: Fluid Therapy. Hemodilution. Pulmonary Edema. Models, Animal. Rats. 


\section{Introduction}

Perioperative fluid replacement has been the focus of much debate. Previously, this debate focused on the various types of fluid components available for replacement therapy, and until recently scientific evidence regarding the amounts of fluid to administer was very scarce. Case series reporting positive outcomes with high-volume fluid resuscitation primarily in trauma settings induced a shifting paradigm in fluid administration regimens extending to elective surgery, from the "restrictive" perioperative fluid regimens widely recommended before the 1950 's to the "liberal" fluid administration practiced today. However, the limited knowledge of the pathophysiology and clinical implications of perioperative fluid management in elective surgical procedures precludes formation of rational guidelines ${ }^{1}$.

It is not possible to estimate with precision during the surgery the loss by evaporation or internal loss for the third space, which affect the estimation of the amount of fluid to be administrated. The usual volume ranges from 2 to $10 \mathrm{ml} / \mathrm{Kg}$ of saline solution per hour of surgery which can mislead resulting dehydration or serious volume overload mainly in critical patients. The normal kidney could correct the excess of water and electrolytes but within certain limits ${ }^{2}$.

The high-volume fluid infusion aims to reduce the circulation of antidiuretic hormone and aldosterone interfering in the trauma response (surgery). It's also capable of reducing the incidence of alkalosis after the surgery when compared to other methods of fluid therapy (restrictive and replacement according to balance), since the alkalosis is the predominant acid-base imbalance on 1 st to 3 rd day after surgery ${ }^{3}$.

The rapid infusion of crystalloids generates other phenomenon also well studied: the hemodilution ${ }^{4}$. This technique evidenced very effective in the prevention of thrombosis in vascular microanastomosis ${ }^{5}$ and possibly could benefit patients in the prevention of pulmonary thromboembolism in plastic surgeries ${ }^{6}$.

Therefore, the objective of this study is to describe an animal model of rapid intravenous (IV) infusion with different volumes of crystalloid, and discuss the clinical findings.

\section{Methods}

Fifty six adult male Wistar rats were used, weighting from $280 \mathrm{~g}$ to $360 \mathrm{~g}$ (mean of $318 \mathrm{~g} \pm 4$ ). All rats were fed with a standard chow and water without restriction until the time of anesthesia. The use of laboratory animals followed the Council for
International Organization of Medical Sciences (CIOMS) ethical code for animal experimentation and the Brazilian College on Animal Experimentation.

The rats were randomly divided into seven groups of eight animals. All rats were subjected to rapid IV infusion of Ringer's lactate (RL) according to the group which it belonged. The volume of crystalloid infused changed in proportion to the body mass of each animal, with a corresponding increase to $50 \%$ of the original blood volume (BV) between one group and another, following the formula: $V i=B W x G \times 0.027$. Where $V i$ is the volume of infusion $(\mathrm{ml}), B W$ is the rat body weight $(\mathrm{g}), G$ is the group number and 0.027 is the constant corresponding to half the blood volume per gram of body weight $(\mathrm{ml} / \mathrm{g})$. The estimated blood volume of the rat was considered $5.4 \mathrm{ml} / 100 \mathrm{~g}$ body weight. In the group 0 there was not fluid infusion $(\mathrm{Vi}=0)$ constituting the control group (SHAM). The mean of administered volume and weight of each group of animals are described with details in Table 1.

TABLE 1 - Groups with the respective rat weights and infusion volume.

\begin{tabular}{|c|c|c|c|}
\hline Group & $\mathbf{n}$ & Weight $(\mathbf{g})$ & $\begin{array}{c}\text { Infusion volume } \\
(\mathbf{m l})\end{array}$ \\
\hline 0 (SHAM) & 8 & $\boldsymbol{x} \pm \mathbf{S D}$ & $\boldsymbol{x} \pm \mathbf{S D}$ \\
\hline $1(0.5 \mathrm{BV})$ & 8 & $327 \pm 26$ & $0.3 \pm 0.7$ \\
\hline $2(1 \mathrm{BV})$ & 8 & $325 \pm 24$ & $17.6 \pm 1.3$ \\
\hline $3(1.5 \mathrm{BV})$ & 8 & $311 \pm 23$ & $25.2 \pm 1.8$ \\
\hline $4(2 \mathrm{BV})$ & 8 & $317 \pm 25$ & $34.2 \pm 2.7$ \\
\hline $5(2.5 \mathrm{BV})$ & 8 & $315 \pm 24$ & $42.5 \pm 3.2$ \\
\hline $6(3 \mathrm{BV})$ & 8 & $326 \pm 25$ & $52.7 \pm 4$ \\
\hline
\end{tabular}

$\mathrm{n}=$ number of animals in each group; $x=$ mean; $\mathrm{SD}=$ standard deviation

Each rat was anesthetized with intraperitoneal administration of ketamine $80 \mathrm{mg} / \mathrm{Kg}$ and xylazine $5 \mathrm{mg} / \mathrm{Kg}$ individually and immediately before the procedure. During the entire experiment the animal remained without any additional oxygen support. At this moment started the monitoring of heart rate $(\mathrm{HR})$, respiratory rate $(\mathrm{RR})$ and saturation of peripheral oxygen $\left(\mathrm{SpO}_{2}\right)$. The device used was the Care Vision OM-100 by IMFtec (Sao Paulo, Brazil) with pediatric sensor.

One longitudinal and other transverse incisions were made on the skin of cervical region, joining each other like an inverse " $T$ ". The fascial and muscular dissection were made with a delicate curve scissors to expose the jugular veins. The left jugular vein was isolated and punctured with an IV plastic catheter device of 24 gauges $\left(\right.$ Abbocath $^{\circledR}$ like) at an angle of $45^{\circ}$, with aspiration of $0.4 \mathrm{ml}$ of blood (Figure 1). By the end of the aspiration it was determined the first evaluation time $\left(\mathrm{T}_{1}\right)$ and also noted the values 
of $\mathrm{HR}, \mathrm{RR}$ and $\mathrm{SpO}_{2}$. The next step was the administration of RL with the volume previously calculated for each animal at a speed of $25 \mathrm{ml} / \mathrm{min}$ (maximum allowed by the catheter diameter).

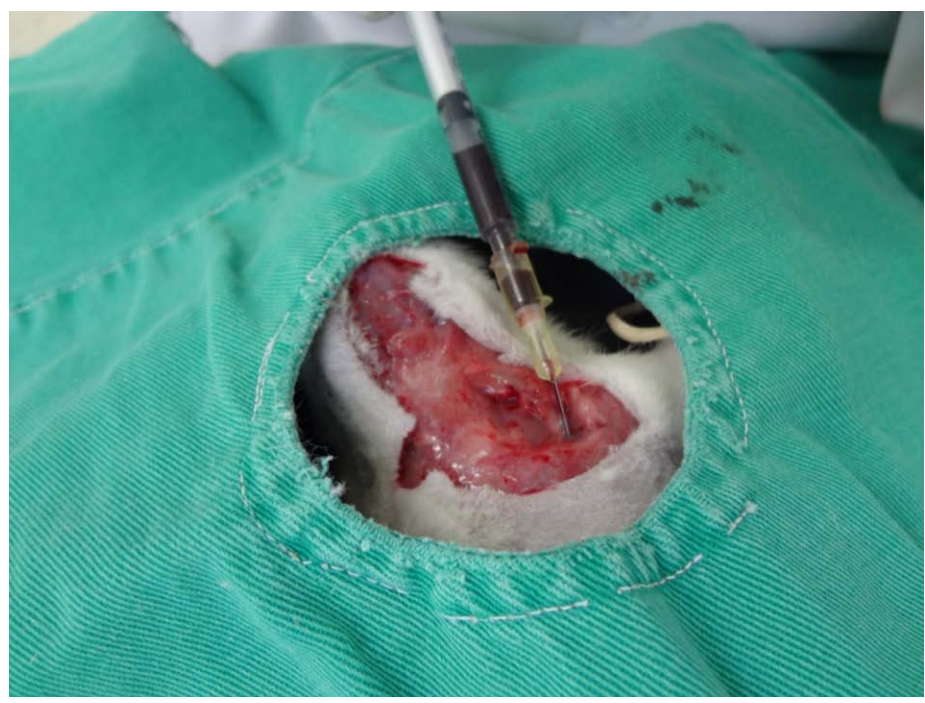

FIGURE 1 - Puncture of the left jugular vein.

Immediately after the final infusion began the observation period of 10 minutes. By the end of this period or death it was established the second evaluation time $\left(\mathrm{T}_{2}\right)$. All the signals were noted again, and the observation of respiratory arrest or death occurrence. It was considerate as respiratory arrest the temporary interruption of the ventilation cycle, with a spontaneous return within one minute. Death was considered as the definitive interruption of the ventilation cycle combined to the pulse absence for more than five minutes.

The statistical evaluation was conducted in order to compare the results of each group relative to the control (SHAM). The variables were presented through difference, mean and standard deviation. It was calculated the differences between the times $\left(T_{1}\right.$ e $\left.T_{2}\right)$, and the comparison between the groups was performed by an analysis of variance, followed by Dunnett's test (comparison to the control). It was used an analysis of variance (ANOVA) to validate the incidence of respiratory arrest and death. The findings were significant at the 0.05 level.

\section{Results}

There was a large variation in respiratory rate of animals before and after the procedure. The average number of breathes per minute before the procedure ranged from 65 (group 2) to 87 (group 0), nearly $35 \%$ of the difference for the time $\mathrm{T}_{1}$ - Table 2.
TABLE 2 - Means and standard deviations of the respiratory rate in $T_{1}, T_{2}$ and the difference between the means in the groups.

\begin{tabular}{|l|l|l|l|l|l|l|l|}
\hline & Group 0 & Group 1 & Group 2 & Group 3 & Group 4 & Group 5 & Group 6 \\
& $\boldsymbol{x} \pm$ SD & $\boldsymbol{x} \pm$ SD & $\boldsymbol{x} \pm$ SD & $\boldsymbol{x} \pm$ SD & $\boldsymbol{x} \pm$ SD & $\boldsymbol{x} \pm$ SD & $\boldsymbol{x} \pm$ SD \\
\hline $\mathrm{T}_{1}(\mathrm{bm})$ & $87 \pm 27$ & $83 \pm 20$ & $65 \pm 25$ & $84 \pm 20$ & $69 \pm 20$ & $66 \pm 10$ & $72 \pm 22$ \\
\hline $\mathrm{T}_{2}(\mathrm{bm})$ & $63 \pm 9$ & $62 \pm 23$ & $54 \pm 35$ & $58 \pm 16$ & $54 \pm 20$ & $44 \pm 38$ & 0 \\
\hline Dif & -24 & -21 & -11 & -26 & -15 & -22 & -72 \\
\hline$p$ & $\mathrm{n} / \mathrm{a}$ & 0.9995 & 0.7185 & 1 & 0.923 & 1 & $\mathbf{0 . 0 0 1 4}$ \\
\hline
\end{tabular}

$x=$ mean; $\mathrm{SD}=$ standard deviation; $\mathrm{bm}=$ breathes per minute; $\mathrm{Dif}=$ difference between T1 and T2; Dunnett's test.

The heart rate average in the groups ranged from 233 bpm (group 2) to $288 \mathrm{bpm}$ (group 0) difference a little less than $25 \%$. There was a significant reduction in the groups 4,5 and 6 (Table 3).

TABLE 3 - Means and standard deviations of the heart rate in $\mathrm{T}_{1}, \mathrm{~T}_{2}$ and the difference between the means in the groups.

\begin{tabular}{|c|c|c|c|c|c|c|c|}
\hline & Group 0 & Group 1 & Group 2 & Group 3 & Group 4 & Group 5 & Group 6 \\
\hline & $x \pm$ SD & $x \pm$ SD & $x \pm$ SD & $x \pm$ SD & $x \pm \mathrm{SD}$ & $x \pm$ SD & $x \pm$ SD \\
\hline $\mathrm{T}_{1}(\mathrm{bpm})$ & $\begin{array}{l}288 \pm \\
25\end{array}$ & $\begin{array}{l}267 \pm \\
49\end{array}$ & $\begin{array}{l}233 \pm \\
37\end{array}$ & $252 \pm 50$ & $276 \pm 35$ & $271 \pm 32$ & $282 \pm 20$ \\
\hline $\mathrm{T}_{2}(\mathrm{bpm})$ & $\begin{array}{l}292 \pm \\
23\end{array}$ & $\begin{array}{l}240 \pm \\
60\end{array}$ & $\begin{array}{l}201 \pm \\
63\end{array}$ & $201 \pm 68$ & $182 \pm 53$ & $105 \pm 96$ & 0 \\
\hline Dif & 4.2 & -26.7 & -31.5 & -51 & -93.3 & -166 & -281.7 \\
\hline$P$ & $\mathrm{n} / \mathrm{a}$ & 0.7523 & 0.6324 & 0.2173 & 0.0055 & $\begin{array}{l}< \\
0.0001\end{array}$ & $\begin{array}{l}< \\
0.0001\end{array}$ \\
\hline
\end{tabular}

$x=$ mean $; \mathrm{SD}=$ standard deviation $; \mathrm{bpm}=$ beats per minute Dif $=$ difference between T1 and T2; Dunnett's test.

The average of peripheral oxygen saturation in $\mathrm{T}_{1}$ measured by oximetry sensor ranged from $79 \%$ (group 5) to $94 \%$ (group 1).After fluid infusion only the groups 5 e 6 presented a significant change between $T_{1}$ and $T_{2}$ comparing with the control group Table 4.

TABLE 4 - Means and standard deviations of the saturation of peripheral oxygen in $\mathrm{T}_{1}, \mathrm{~T}_{2}$ and the difference between the means in the groups.

\begin{tabular}{|l|l|l|l|l|l|l|l|}
\hline & Group 0 & Group 1 & Group 2 & Group 3 & Group 4 & Group 5 & Group 6 \\
\hline & $\boldsymbol{x} \pm$ SD & $\boldsymbol{x} \pm$ SD & $\boldsymbol{x} \pm$ SD & $\boldsymbol{x} \pm$ SD & $\boldsymbol{x} \pm$ SD & $\boldsymbol{x} \pm$ SD & $\boldsymbol{x} \pm$ SD \\
\hline $\mathrm{T}_{1}(\%)$ & $87 \pm 5$ & $94 \pm 5$ & $89 \pm 7$ & $84 \pm 11$ & $88 \pm 9$ & $79 \pm 9$ & $85 \pm 7$ \\
\hline $\mathrm{T}_{2}(\%)$ & $89 \pm 6$ & $88 \pm 9$ & $72 \pm 16$ & $65 \pm 22$ & $69 \pm 18$ & $54 \pm 35$ & 0 \\
\hline Dif & 2 & -6 & -17 & -19 & -19 & -25 & -85 \\
\hline $\mathrm{p}$ & $\mathrm{n} / \mathrm{a}$ & 0.907 & 0.2324 & 0.1655 & 0.1613 & $\mathbf{0 . 0 4 2 8}$ & $<$ \\
\hline
\end{tabular}

$x=$ mean $; \mathrm{SD}=$ standard deviation; Dif $=$ difference between T1 and T2; Dunnett's test. 
A respiratory arrest was detected after fluid administration in $50 \%$ of the animals in the group 3 and $100 \%$ of animals in the groups 4,5 and 6 . This arrest was temporary $(<1$ minute) in all of the animals of group 3 and 4 , and $75 \%$ of the animals in the group 5. In these cases the animals returned to breathe spontaneously without any intervention or assistance. In $25 \%$ of the animals in the group 5 and a $100 \%$ in group 6 the respiratory arrest was final, and the rats died. All of animals in the groups 0, 1, 2, 3 and 4 remained alive and they were euthanized to the end of the experiment. The Figure 2 displays the respiratory arrest and death occurrence in each group.

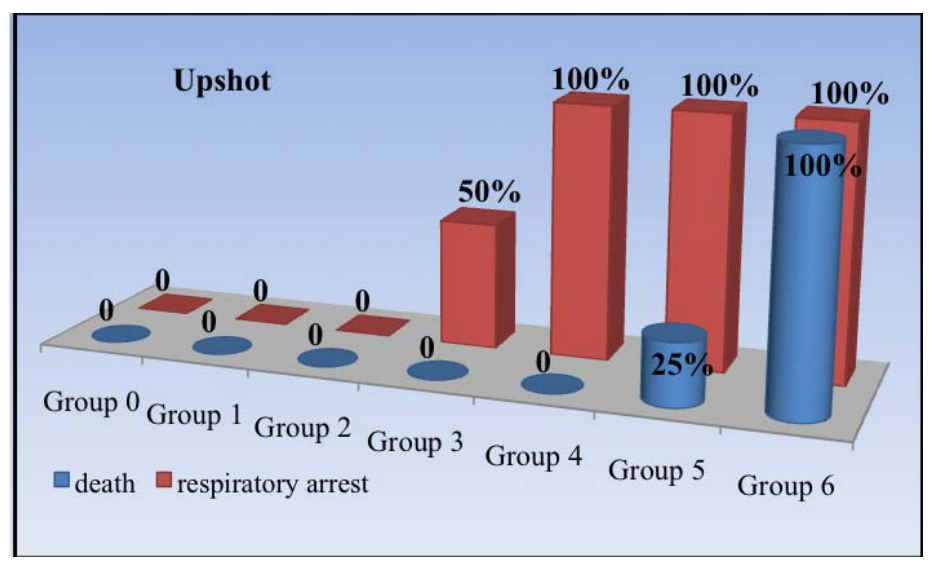

FIGURE 2 - Incidence of respiratory arrest and death in the groups $(p<0.0001$ - ANOVA).

\section{Discussion}

The description of an experimental model of intravenous bolus of fluid involves determining a threshold of toxicity, in other words, when the subject begins to present significant and potentially lethal clinical alterations. This research studied these effects and it was possible to identify at what moment each one of the parameters change significantly.

To avoid possible bias in relation to the amount of fluid administered in each animal, it followed a formula that considered body mass and the group that it belongs to. Using an adjustment index (5.4 $\mathrm{ml}$ of blood per each $100 \mathrm{~g}$ of body weight) it was possible to establish a standard method to infuse the appropriate volume in each animal from the different groups.

In 2003 a study presented results of a $0.9 \%$ saline solution infusion in doses of $30 \mathrm{ml} / \mathrm{Kg}$ in twenty minutes in humans. The spirometry and ventilator parameters were observed. In agreement with previous studies the amount of fluid infused was incapable of change the parameters after the fluid overload ${ }^{7}$. The volume of fluid utilized is equivalent to $1.800 \mathrm{ml}$ in an adult human of $60 \mathrm{Kg}$ or $9 \mathrm{ml}$ in a rat of $300 \mathrm{~g}$, in other words, a little more than $50 \%$ of blood volume. Checking the respiratory rate in $T_{1}$ and $T_{2}$ the group corresponding to infusion of 0.5 fold $\mathrm{BV}$ did not presented significant change relative to the control besides that also showed a smaller difference between the times. This may be due to the increase of pulmonary blood and oxygenation improvement as another study suggests ${ }^{8}$. There was a significant difference only in 3 fold BV group, where all animals died, which means that all of them presented $\mathrm{T}_{2}$ equal to zero.

Respiratory rate, therefore, is not an appropriate parameter to evaluate the influence of volume overload. The protocol of anesthesia with ketamine and xylazine interfere with the animal's respiratory rate reducing more or less in each individual. This heterogeneity of effect on ventilator system caused by anesthesia may have affected significantly the results of this parameter, remembering that xylazine is a muscle relaxant drug and can act even a little in the diaphragm and intercostals muscles. The $\mathrm{SpO}_{2}$ ranged in $T_{1}$ from $79.1 \%$ (group 5) to $93.8 \%$ (group 1). This could be one more indicative data from an interference of anesthesia on ventilatory mechanics.

Another paper describes the effects of the rapid infusion of $2.000 \mathrm{ml}$ of saline solution in humans, the evaluation was made in three times: during the administration, 10 and 20 minutes after. This volume did not cause any respiratory symptom or signal such as dyspnea or crackles. The spirometry results indicated that there was an increase in the extra vascular lung water. The heart rate of the patients did not change despite the increase in the cardiac output from $4.67 \mathrm{l} / \mathrm{min}$ (before) to $6.11 / \mathrm{min}(20 \mathrm{~min})^{8}$. Differently from described, in this study the animals presented a reduction of $10 \%$ in the heart rate in group 1 , which was progressively larger in subsequent groups. This can be explained by the circulatory physiology where the cardiac output is a product of stroke volume by heart rate ${ }^{9}$. As stroke volume increased due to increased BV, the heart rate tends to low stabilizing the cardiac output.

Those authors ${ }^{8}$ also observed a drop in the $\mathrm{SpO}_{2}$ value despite not having found important changes in the blood gases pressures. This finding was attributed to the lower concentration of oxygen in the blood, a natural consequence of hemodilution, which does not cause a reduction in the oxygenation of the tissues. In this study the $\mathrm{SpO}_{2}$ value indicated by pulse oximetry was progressively lower presenting significant difference only in the groups 5 e 6 . Muir et al. ${ }^{8}$ also describe dissociation in the drop of $\mathrm{SpO}_{2}$ and the $\mathrm{pO}_{2}$ value, suggesting the $\mathrm{SpO}_{2}$ is not a reliable parameter in hemodiluted patients.

Lower airways resistance was partitioned and lung morphology studied in dogs under controlled vascular conditions. It was observed that as left atrial pressure was increased, peripheral 
airways resistance showed a gradual increase which was reversible if the atrial pressure was not raised above $15 \mathrm{mmHg}$; and above this value the peripheral airways resistance rose more steeply and was no longer reversible ${ }^{10}$. That finding probably explains the progressive presence of respiratory arrest and death in the animals of this study; the respiratory arrest was transitory in the groups 3 and 4 , which rats possibly have not reached the left atrial pressure equivalent to $15 \mathrm{mmHg}$ described in dogs. In the group 5 some of them $(25 \%)$ showed an irreversible respiratory arrest and died. In the group 6 all animals died.

The method and results from this experimental model can be used in researches that involve fluid administration in large amount such as bleeding, shock, coagulation disorder, thrombosis prevention, hemodilution, fluid management and overload studies.

The clinical findings of the rapid intravenous infusion of large volumes of fluid were described. The effects of the maintenance of this hypervolemia need further researches. Offering additional oxygen by a nasal catheter, mask or endotracheal tube possibly results in new data and conclusions. The extrapolation of this data to the clinical practice in humans should be done carefully.

\section{Conclusions}

It was described an animal model of rapid intravenous infusion with different volumes of crystalloid. The rapid infusion of crystalloid to the same volume of blood volume did not change significantly the heart rate, respiratory, saturation of peripheral oxygen and did not induce respiratory arrest in rats. The fluid administration in the volume of three times the blood volume was lethal to all animals.

\section{References}

1. Holte K, Sharrock NE, Kehlet H. Pathophysiology and clinical implications of perioperative fluid excess. $\mathrm{Br} \mathrm{J}$ Anaesth. 2002;89(4):622-32

2. Ceneviva R, Vicente YAMVA. Equilíbrio hidroeletrolítico e hidratação no paciente cirúrgico. Medicina (Ribeirão Preto). 2008;41(3):287-300.

3. Moriya T, Martins ACP, Cherri J, Piccinato CE, Okano N, Carneiro JJ, Iwakura R. Hidratação e equilíbrio ácido-base em pacientes cirúrgicos. Acta Bras Cir. 2000;15(Supl 2):34-8.

4. Messmer K. Hemodilution. Surg Clin North Am. 1975;55(3):65978.

5. Farina JA, Piccinato CE, Rossi MA, Mazzer N, Llorach-Velludo MA Effect of isovolemic hemodilution with 3\% albumin on thrombus formation at venous microanastomosis in rats. Microsurgery. 2002;22:152-7.

6. Viterbo F, Siclovan H. Prevention of thromboembolism by saline solution perfusion. Aesth Plast Surg. 2006;30:629-30.
7. Pellegrino R, Dellaca R, Macklem PT, Aliverti A, Bertini S, Lotti P, Agostoni PG, Locatelli A, Brusasco V. Effects of rapid saline infusion on lung mechanics and airway responsiveness in humans. J Appl Physiol. 2003;95:728-34.

8. Muir AL, Flenley DC, Kirby BJ, Sudlow MF, Guyatt AR, Brash HM. Cardiorespiratory effects of rapid saline infusion in normal man. J Appl Physiol. 1975;38:786-93.

9. Horster S, Stemmler HJ, Strecker N, Brettner F, Hausmann A, Cnossen J, Parhofer KG, Nickel T, Geiger S. Cardiac output measurements in septic patients: comparing the accuracy of USCOM to PiCCO. Crit Care Res Pract. 2012;2012:270631.

10. Hogg JC, Agarwal JB, Gardiner AJS, Palmer WT, Macklem PT. Distribution of airway resistance with developing pulmonary edema in dogs. J Appl Physiol. 1972;32:20-4.

\section{Acknowledgments}

To Prof. Mariângela Marques (Department of Pathology) and Prof. José Corrente (Research Support Group) of Faculty of Medicine of Botucatu, UNESP.

\section{Correspondence:}

Fausto Viterbo

Rua Domingos Minicucci Filho, 587

18607-030 Botucatu - SP Brasil

Tel.: (55 14)3882-5414

fv@,faustoviterbo.com.br

Received: December 5, 2012

Review: February 8, 2013

Accepted: March 11, 2013

Conflict of interest: none

Financial source: Sao Paulo Research Foundation (FAPESP)

${ }^{1}$ Research performed at Laboratory of Department of Surgery and Orthopedics, Faculty of Medicine of Botucatu, Sao Paulo State University (UNESP), Brazil. Part of Master degree thesis, Postgraduate Program in Surgery Bases. Tutor: Prof. Fausto Viterbo. 